\title{
Empoderamiento docente para la integración de las TIC en la práctica pedagógica, a partir de la problematización del saber matemático*
}

\author{
Sonia Valbuena Duarte ${ }^{\mathrm{a}}$ Adriana Patricia Medina Güette ${ }^{\mathrm{b}}$ - Valentina Saray \\ Teherán Barrancoc
}

Resumen: la investigación tuvo como objetivo identificar los elementos constituyentes del empoderamiento docente para la integración de las Tecnologías de la Información y la Comunicación (TIC) en la enseñanza de la matemática, desde la problematización del saber matemático. Para realizar la investigación se hizo uso de un estudio de casos múltiples, se realizó una revisión documental para leer en forma cruzada una serie de documentos que permitieron identificar características del empoderamiento docente y su relación con el uso pedagógico de la tecnología en el aula de matemáticas. Con base en dichos elementos se estructuraron entrevistas y observaciones aplicadas a formadores de licenciados en matemáticas, licenciados en matemáticas en formación inicial y docentes en ejercicio en el área de matemáticas. A partir de las entrevistas y las observaciones no participantes aplicadas a la muestra objeto de estudio, se revela que existe una divergencia, particularmente en el conocimiento de recursos tecnológicos y su uso en cuanto a lo pedagógico y didáctico; por tanto, se concluye que, aunque se reconoce la tecnología como herramienta de apoyo a los procesos de enseñanza y aprendizaje, se hace necesario reforzar las competencias pedagógicas, didácticas y tecnológicas como aspectos importantes dentro del proceso de empoderamiento docente, especialmente por parte de los profesores en ejercicio, en lo referente al uso didáctico y pedagógico de la tecnología.

Palabras clave: formación de profesores; enseñanza; TIC; competencias digitales

Recibido: 24 de julio de 2020

Aceptado: 30 de noviembre de 2020

Disponible en línea: 28 de mayo de 2021

* Artículo de investigación.

a Magíster en Educación y en Matemática. Universidad del Atlántico, Barranquilla, Colombia. Correo electrónico: soniabalbuena@mail.uniatlantico.edu.co ORCID: https://orcid.org/0000-0003-3667-1087

b Estudiante de licenciatura en Matemáticas. Universidad del Atlántico, Barranquilla, Colombia. Correo electrónico: apatriciamedina@mail.uniatlantico.edu.co ORCID: https://orcid.org/0000-0002-1654-1026

c Estudiante de licenciatura en Matemáticas. Universidad del Atlántico, Barranquilla, Colombia. Correo electrónico: vteheran@mail.uniatlantico.edu.co ORCID: https://orcid.org/0000-0001-8193-4873 
Cómo citar: Valbuena, S., Medina A. P. y Teherán V. S. (2021). Empoderamiento docente de las TIC a partir de la problematización del saber matemático. Academia y Virtualidad, 14(1), 41-62. https://doi.

org/10.18359/ravi.5161

\title{
Teaching Empowerment for the Integration of ICT into the Pedagogical Practice, Based on the Problematization of Mathematical Knowledge
}

\begin{abstract}
: the research aimed to identify the constituent elements of teachers empowerment for the integration of Information and Communication Technologies (ICT) into the teaching of mathematics, from the problematization of mathematical knowledge. A multi-case study was used to conduct the research, a documentary review was also conducted to cross-read a series of documents that identified characteristics of teacher empowerment and their relationship to the pedagogical use of technology in the classroom. Based on these elements, interviews and observations were structured and applied to graduate math educators, graduates in mathematics in initial training and teachers in practice in the area of mathematics. From the interviews and non-participating observations applied to the sample under study, it is revealed that there is a divergence, particularly in the knowledge of technological resources and their use in terms of pedagogical and didactic; it is concluded that, although technology is recognized as a tool to support teaching and learning processes, it is necessary to strengthen pedagogical, didactic and technological competences as important aspects within the process of teacher empowerment, especially by working teachers, with regard to the didactic and pedagogical use of technology.
\end{abstract}

Keywords: teacher training; teaching; ICT; digital skills

\section{Empoderamento docente para integrar as TIC na prática pedagógica, a partir da problematização do saber matemático}

Resumo: o objetivo desta pesquisa foi identificar os elementos constituintes do empoderamento docente para integrar as tecnologias da informação e da comunicação (TIC) no ensino da matemática, a partir da problematização do saber matemático. Para realizar a pesquisa, utilizou-se um estudo de casos múltiplos, realizou-se uma revisão documental para ler em forma cruzada documentos que permitiram identificar características do empoderamento docente e sua relação com o uso pedagógico da tecnologia na aula de matemática. Com base nesses elementos, foram estruturadas entrevistas e observações aplicadas a formadores de licenciados em matemática, em matemática em formação inicial e docentes em exercício na área de matemática. A partir das entrevistas e das observações não participantes aplicadas à amostra objeto de estudo, revela-se que existe uma divergência, particularmente no conhecimento de recursos tecnológicos e seu uso quanto ao pedagógico e ao didático. Portanto, conclui-se que, embora a tecnologia seja reconhecida como ferramenta de apoio aos processos de ensino-aprendizagem, é necessário reforçar as competências pedagógicas, didáticas e tecnológicas como aspectos importantes do processo de empoderamento docente, especialmente por parte dos professores em exercício, no que se refere ao uso didático e pedagógico da tecnologia.

Palavras-chave: formação de professores; ensino; TIC; competências digitais 


\section{Introducción}

En investigaciones como la de Llinares (2012; 2018) y Moreno (2019) se evidencia que desde hace varios años hay poca presencia de las competencias pedagógicas, didácticas y tecnológicas dentro de la práctica docente, lo que ha llevado a que la investigación educativa se enfoque en analizar y comprender el verdadero papel del profesor en el proceso de enseñanza y aprendizaje, particularmente de las matemáticas y en su desarrollo profesional.

Por otro lado, Rodríguez (2016) afirma que la educación matemática no solo debe promover los procesos cognitivos individuales, al punto de negar la subjetividad del estudiante, el contexto donde se interactúa y el proceso educativo. De esta manera, se considera que las aulas de clase matemáticas no son solo productoras de conocimiento, sino también de subjetividades, siendo la contextualización y la ubicación del estudiante en estos procesos necesarios dentro de la función social de la enseñanza de las matemáticas (Radford, 2018). Sin embargo, el docente no involucra el contexto donde se encuentra inmerso el estudiante, su cotidianidad entre otros aspectos, al momento de preparar una clase, generando en él desinterés por el aprendizaje de las matemáticas.

El Ministerio de Educación Nacional (MEN, 2014) en Colombia plantea que el maestro debe estar comprometido con su disciplina y con sus estudiantes para que comprenda qué es lo que enseñará, que sea capaz de conocer el contexto donde lo va a enseñar y, además, pueda precisar y diseñar cómo debe enseñarlo para lograr en los estudiantes la comprensión y apropiación de los saberes que enseña. Sin embargo, Cantoral y Reyes-Gasperini (2012a) consideran que el cambio en la práctica pedagógica del docente se complejiza, puesto que no se evidencia la integración de las dimensiones del saber y los componentes de la construcción social, lo que impide que el docente se adueñe del saber que enseña, generando así falta de confianza y autonomía para abrir caminos a la innovación y para suscitar de reflexiones con sus estudiantes.

Los cambios que se han venido presentando en la sociedad han exigido que se fortalezca la actual realidad educativa, es decir, se debe replantear las propuestas educativas y pedagógicas, con el fin de involucrar al individuo en el proceso, teniendo en cuenta sus necesidades y su relación con el entorno (Alvis et al. 2019). Para el sistema educativo es un fin deseable que todos, o tantos como sea posible, aprendan matemáticas mediante pedagogías apropiadas que respondan pertinentemente al desarrollo científico y tecnológico que se vive en las sociedades actuales. Esto se condensa en la idea de que las matemáticas empoderan a quien las aprende (Valero, 2017).

Por otro lado, las Tecnologías de la Información y la Comunicación (TIC) se han convertido en una de las formas más tangibles para acceder a la sociedad del conocimiento, eficaces para motivar al estudiante a ser protagonista de su aprendizaje, y en particular tienen potencial para mejorar el aprendizaje de las matemáticas; al mismo tiempo, la sociedad del conocimiento exige cada vez más el desarrollo de las capacidades y habilidades tecnológicas en estudiantes y docentes (Molina e Iglesias, 2014; Torres, 2017). Por tanto, las competencias y metodologías en el uso de las Tic de los docentes son un factor importante para que estos cumplan un papel de orientador y no de dictador, es decir, los maestros se deben profesionalizar y capacitar para el uso significativo de la tecnología (Banoy, 2019; Thurm y Barzel, 2020).

Actualmente, la necesidad de tomar medidas de distanciamiento social por la propagación del coronavirus COVID-19 ha generado gran impacto en todos los sectores de la sociedad a nivel internacional, en especial en el sector educativo, dado que ha obligado a que las instituciones educativas se adapten rápidamente a la situación, en busca de soluciones urgentes, a través de plataformas virtuales, por lo cual se ha incrementado el uso de recursos tecnológicos como las TIC para mitigar los efectos de propagación del virus en la población educativa (Jandric, 2020; Teräs et al., 2020). Por tanto, las exigencias para los docentes de educación presencial en materia del uso de recursos tecnológicos se han duplicado, puesto que están en la obligación de utilizarlos para seguir cumpliendo con el servicio educativo.

Ante la obligación del sistema educativo de apoyarse en la enseñanza virtual, particularmente para 
las instituciones de carácter meramente presencial, se han despertado una serie de interrogantes de tipo pedagógico, que involucran directamente al docente y su rol en este nuevo ambiente escolar, más allá de la cuestión de contar con suficiente infraestructura tecnológica o no. Interrogantes que nos llevan a reflexionar sobre si los docentes poseen las características y saberes para responder de forma pertinente a la enseñanza remota, o si simplemente las aulas presenciales están siendo reproducidas en la virtualidad.

Por consiguiente, esta investigación se justifica desde el concepto de empoderamiento docente, el cual pretende que los profesores y licenciados en formación reconozcan la importancia de apropiarse los saberes disciplinares y pedagógicos para la transformación de su práctica, potencializando e innovando sus aprendizajes de tal manera que promuevan el logro de aprendizajes óptimos en sus estudiantes. En este sentido, la intención de la investigación es contribuir a que el docente, por medio del empoderamiento de sus saberes, sea capaz de generar ambientes innovadores de aprendizaje implementando herramientas TIC, teniendo en cuenta su relevancia y múltiples usos dentro de la sociedad actual.

No obstante, Grisales-Aguirre (2018) sostiene que las TIC no se pueden considerar la solución a los problemas educativos por sí solas; aunque facilitan los procesos de enseñanza, es el docente quien debe apropiárselas y darles el debido uso. La integración eficaz de las Tic en el entorno de aprendizaje dependerá de la capacidad de los educadores para estructurar el aprendizaje de forma innovadora, combinar adecuadamente la tecnología con una pedagogía, desarrollar la actividad social en el aula, y fomentar la cooperación, el aprendizaje colaborativo y el trabajo en grupo (Unesco, 2019).

Por tanto, se hace pertinente analizar y cuestionar la manera en que el sistema educativo, en particular los docentes y formadores de docentes, aprovechan este tipo de herramientas para potencializar los contenidos y diseñar actividades con el fin de promover el aprendizaje autónomo del estudiante, puesto que al parecer aún no hay mucha consciencia sobre lo eficaces que pueden ser las TIC en los procesos de enseñanza y aprendizaje, siendo estas una propuesta innovadora y de posibles cambios significativos en la educación.

Cantoral y Reyes-Gasperini (2012b) se cuestionan acerca de “¿cuál es el proceso que debe vivir el docente para acompañar e incorporarse a esta nueva visión del aprendizaje de la matemática? ¿Qué proceso debe vivir el docente para lograr la apropiación del saber matemático mediante su problematización, para modificar su práctica?”. Como respuesta a esto, se considera indispensable el empoderamiento docente para lograr la apropiación del saber matemático por medio de su problematización, un cambio significativo en su práctica docente, haciendo uso de las TIC. Es por esto que para esta investigación se planteó como interrogante: ¿qué elementos constituyen el empoderamiento docente de las Tic en la enseñanza de la matemática?

\section{Políticas que sustentan la integración de las TIc en la educación en Colombia}

En la Ley General de la Educación (1994) de Colombia, en los artículos 23 y 31, se establece que, dentro de las áreas obligatorias y fundamentales para el logro de los objetivos de la educación básica y media que necesariamente se ofrecen de acuerdo con el currículo y el Proyecto Educativo Institucional, se encuentra la Tecnología e informática. Dicha ley le dió vida al Plan Nacional Decenal de Educación (PNDE). Actualmente se encuentra vigente el PNDE 2016-2026, donde se exponen diez desafíos para el país en materia de educación. Particularmente, como sexto desafío propone "impulsar el uso pertinente, pedagógico y generalizado de las nuevas y diversas tecnologías para apoyar la enseñanza, la construcción de conocimiento, el aprendizaje, la investigación y la innovación, fortaleciendo el desarrollo para la vida" (p. 51). Esto implica la reestructuración de lineamientos de calidad, que comprometa a los distintos actores y tenga en cuenta la diversidad de los contextos.

Expuesto lo anterior, cabe agregar que la Ley 1341 de 2009 de Colombia define a las Tecnologías de la Información y la Comunicación (TIC) como el conjunto de recursos, herramientas, equipos, programas informáticos, aplicaciones, redes y medios 
que permiten la compilación, procesamiento, almacenamiento, transmisión de información como voz, datos, texto, video e imágenes. Dentro de los lineamientos para la integración de TIC en ambientes educativos, se proponen básicamente tres objetivos; así, se hace énfasis en la dotación de infraestructura tecnológica, el intercambio y producción de información mediados por TIC, y la formación de profesores en el uso pedagógico de estas, para abrir camino a la calidad de la educación (López et al. 2017).

En el año 2013 el MEN expide el documento de Competencias TIC para el desarrollo profesional docente, cuyo objetivo es guiar el proceso de desarrollo profesional docente para la innovación educativa pertinente con uso de TIC. En este sentido, el MEN define la competencia como un saber hacer flexible que puede actualizarse en distintos contextos, es decir, la capacidad de usar los conocimientos en situaciones distintas de aquellas en las que se aprendieron. Este concepto implica la comprensión del sentido de cada actividad y sus implicaciones éticas, sociales, económicas y políticas (MEN, 2006). Así, las competencias que deben desarrollar los docentes dentro del contexto específico de la innovación educativa con uso de TIC son: competencia tecnológica, competencia comunicativa, competencia de gestión, competencia pedagógica y competencia investigativa (MEN, 2013).

Por otra parte, en el Artículo 2.5.3.2.3.2.9 del Decreto 1330 del 2019, el MEN plantea que la institución educativa deberá contar con la dotación de los ambientes presenciales o virtuales de aprendizaje que incorporan equipos, mobiliario, plataformas tecnológicas, sistemas informáticos o los que hagan sus recursos bibliográficos físicos y digitales, de datos, recursos de aprendizaje e información, entre otros, que atienden los procesos formativos, el desarrollo la investigación y la extensión.

En el margen de la problemática actual que vive el mundo frente a la emergencia sanitaria por el COVID-19 declarada por la Organización Mundial de la Salud (oms), el MEN (2020) en la circular número 020 implementó medidas adicionales para manejar, controlar y prevenir la propagación del COVID-19. Dentro de estas, puso a disposición de los directivos y docentes de todas las áreas una plataforma con recursos educativos abiertos cuyo objetivo es apoyar los procesos de aprendizaje en los estudiantes de los diferentes niveles educativos, esta plataforma se denomina "Aprender Digital: contenidos para todos", el cual ofrece más de 80 mil recursos educativos digitales. De igual manera, ha capacitado a más de 4.000 tutores del programa "Todos a Aprender", con mediación de las TIC, para hacer acompañamiento a los docentes en el desarrollo de actividades en casa, en el área de lenguaje, matemáticas y educación inicial, que permitan apoyar los procesos de planeación de la práctica pedagógica de los docentes, teniendo en cuenta el contexto social, cultural y pedagógico.

\section{Empoderamiento docente, un medio para la integración de las TIC en la práctica pedagógica}

Cantoral y Reyes-Gasperini (2014) consideran que el empoderamiento se entiende como un "fenómeno" de carácter social que se ha estudiado desde diferentes disciplinas, caracterizado por la necesidad del trabajo colectivo, que pretende generar a través de la reflexión reacciones en la práctica. Dentro del contexto educativo, Cantoral y Reyes-Gasperini (2012a, 2012b, 2016) conciben el empoderamiento como el proceso que debe vivir el docente e investigador de manera conjunta, que permite "adueñarse" del saber que se enseña mediante la problematización, y que genera confianza y autonomía, lo que permite abrir paso a la innovación, generación de cuestionamientos, debates y reflexiones con sus estudiantes.

Cuando se habla de problematización del saber matemático, (PSM) Reyes-Gasperini y Cantoral (2011), Cantoral y Reyes-Gasperini (2016) se refieren a "hacer del saber un problema", analizarlo de manera didáctica con el fin de localizar el uso y razón de ser del conocimiento matemático estudiado. Esto desde la teoría socioepistemológica se fundamenta en la integración entre las dimensiones del saber y los componentes de la construcción social. La relación de estas dimensiones motiva al docente a cuestionar el saber matemático y, posteriormente, problematizar la matemática escolar (PME), es decir, los conocimientos matemáticos 
que para el sistema educativo son los fundamentales. La integración de dichas dimensiones implica analizar: la naturaleza del saber (dimensión epistemológica); el uso del saber (dimensión social); la apropiación del saber (dimensión cognitiva) y la difusión del saber (dimensión didáctica).

En cuanto a las dimensiones mencionadas anteriormente, la dimensión social permite analizar los conocimientos matemáticos; la dimensión funcional, situacional e histórica permite analizar la contextualización real de las situaciones de aprendizaje. La dimensión epistemológica estudia la naturaleza del saber matemático $y$, al igual que la dimensión social, reconoce a la matemática como parte de la cultura, como producto de la actividad humana. La dimensión didáctica se encuentra ligada a los aspectos didáctico-pedagógicos que implican la relación profesor-estudiante, acciones de construcción de significados compartidos y acto de enseñanza, es decir, la manera como se presenta el saber matemático estudiado en el sistema didáctico. En cuanto a la dimensión cognitiva, esta se refiere a los procesos de apropiación del saber matemático y en los que el desarrollo del pensamiento matemático se evidencia en diferentes contextos (Cantoral y Reyes-Gasperini, 2014; 2016)

Gómez (2015) planteó una serie de categorías que caracterizan el empoderamiento docente. Con base en las dimensiones mencionadas, definió las siguientes categorías: saber matemático (dimensión cognitiva y epistemológica), liderazgo grupal (dimensión social), reflexión sobre la práctica docente (dimensión didáctica). Por otro lado, Amaya et al. (2018) afirman que el empoderamiento docente nace a raíz de generar confianza en los profesores universitarios para poder aumentar sus fortalezas, mejorar sus habilidades y capacidades, con el fin de dar respuesta a los desafíos del siglo XXI.

En este sentido, es importante analizar de qué manera los docentes que dominan las competencias digitales pueden implementar con decisión estrategias didácticas y técnicas de enseñanza con una mentalidad creativa e innovadora a través de las TIC, diversificar las opciones de enseñanza y aprendizaje, y complementar la formación profesional de las nuevas generaciones de estudiantes. (Amaya et al., 2018)
Según Fiallo (2015) se deben generar espacios donde los profesores exploren las bondades y limitaciones de incorporar las tecnologías en la práctica docente. Se hace necesario que se hagan reflexiones sobre cuándo y cómo implementarlas. La incorporación de las TIC en la educación, según Lopes y Gomes (2018), está asociada a los cambios en el modo de aprender, en la interacción entre quien aprende y quien enseña, y en el modo cómo se reflexiona sobre la naturaleza del conocimiento. Es conocida la importancia de incorporar las TIC en la enseñanza, de mostrarlas a los futuros docentes, para que haya un aprendizaje de calidad y preparar a los estudiantes en las demandas de la sociedad moderna.

\section{Metodología}

La investigación en la que se basa este artículo es de tipo cualitativo y corresponde a un estudio de casos múltiples (Rule y Mitchell, 2015). Puesto que el objetivo de la investigación es identificar los elementos constituyentes del empoderamiento docente de las TIC en los formadores de formadores $(\mathrm{FF})$, licenciados en formación ( $\mathrm{LF}$ ) y docentes en ejercicio (DE). La presente investigación se estructuró siguiendo una serie de pasos o etapas adaptadas de Naupas et al. (2014) y Jiménez (2012):

- Fase I. El diseño. Esta fase corresponde a elaborar las preguntas básicas para nuestra investigación. Surgen interrogantes sobre el cómo y el porqué de la investigación, entre otros, que ayudan a definir las unidades de análisis, orientar la recolección de datos y delimitar la investigación.

- Fase II. Selección de la muestra. Se seleccionan los aspectos a explorar, y a su vez los sujetos o las personas sobre las que se va a realizar el estudio. En este caso hacen parte formadores de formadores, licenciados en matemáticas en formación inicial de la Universidad del Atlántico y docentes de matemáticas en ejercicio.

- Fase III. La recolección de datos. En esta fase se diseñan y aplican las técnicas e instrumentos seleccionados sobre la muestra, que en el caso de esta investigación son tres: la revisión documental, la entrevista y la observación. 
Con la técnica de revisión documental es posible analizar en qué consiste el empoderamiento docente en educación matemática y qué elementos lo constituyen en relación con el uso de las Tic. Para utilizar esta técnica, se tendrá en cuenta las etapas que plantea Quintana (2006):

1. Rastrear e inventariar los documentos existentes. Se revisan los artículos científicos y trabajos realizados alrededor del fenómeno de empoderamiento docente y de las competencias TIC.

2. Clasificar y seleccionar los documentos identificados. Se seleccionaron artículos científicos y trabajos de investigación de la autoría de Ricardo Cantoral, Daniela Reyes y otros, una tesis doctoral de la Universidad Pedagógica de Monterrey realizada en el año 2015 por Juan Pablo Gómez Estrada, el documento expedido en el año 2013 de competencias TIC para el desarrollo profesional docente del MEN y un artículo de investigación sobre empoderar a los docentes en competencias digitales, publicado en el año 2018, de la autoría de Amaya et al.

3. Leer en profundidad el contenido de los documentos seleccionados para extraer elementos de análisis. En la lectura se enfatizará principalmente en las concepciones de empoderamiento docente, para la caracterización del mismo y de las competencias TIC del docente que proponen los autores en los documentos seleccionados.

4. Leer en forma cruzada y comparativa los documentos en cuestión. Se tomarán las diferentes posturas frente al empoderamiento docente y las características de este para identificar los elementos que lo constituyen en relación con el uso de las TIC.

El segundo instrumento de recolección de datos es la entrevista. Esta técnica fue realizada por medio de dos cuestionarios que constaban de seis y siete interrogantes que abordaban los elementos identificados en la revisión documental.

El último instrumento es el de la observación. Se realizó una observación no participante, con el fin de complementar la información obtenida por la entrevista.
- Fase IV. Elaboración del informe. En esta fase se realizó un análisis de lectura cruzada de textos y una triangulación de datos con las respuestas obtenidas en las entrevistas realizadas. Se elabora el informe final de acuerdo al análisis de datos y la socialización de los resultados de la investigación.

\section{Participantes}

La población seleccionada para esta investigación está constituida por los formadores de formadores y los estudiantes del programa de Licenciatura en Matemáticas de la Universidad del Atlántico que estén realizando prácticas pedagógicas y docentes en ejercicio del Departamento del Atlántico. La muestra se escoge de manera intencional: tres formadores de formadores del programa Licenciatura en Matemáticas identificados como FF1, FF2 y FF3, los cuales se caracterizan por distintas credenciales académicas: $\mathrm{FF} 1$ tiene formación posgradual de especialista en estadística y magíster en gestión de la tecnología educativa, FF2 es especialista en enseñanza de las ciencias y aprendizaje autónomo, y FF3 es magíster en TIC e innovación educativa y magíster en matemáticas. Los tres son profesores catedráticos y de tiempo completo en la Universidad del Atlántico. Se seleccionaron, además, cuatro estudiantes que estaban realizando práctica profesional pedagógica I y II del mismo programa, identificados como LF1, LF2, LF3 y LF4, así como tres docentes en ejercicio en el área de matemáticas de instituciones públicas del Departamento del Atlántico, identificados como DE1, DE2, DE3.

\section{Resultados y discusión}

En esta sección se presentan, de manera detallada, los hallazgos obtenidos desde la revisión documental hasta las entrevistas aplicadas a los participantes. En la Tabla 1 se muestra lo resultante del rastreo de documentos y la lectura cruzada en el marco del Empoderamiento docente y el uso de las Tic. Más adelante, se presenta el análisis de las entrevistas articulado con las observaciones no participantes. 


\section{Análisis de la revisión documental}

Luego de realizar la lectura cruzada de los textos seleccionados para el análisis de la revisión documental, se extrajeron elementos característicos del empoderamiento docente y su relación con el uso de la tecnología. Fueron seleccionados ocho documentos, de los cuales se tomaron unas dimensiones del saber adaptadas de los documentos con autoría de Cantoral y Reyes-Gasperini (2014), Cantoral, Reyes-Gasperini, y Montiel, G. (2013) y Reyes-Gasperini y Cantoral (2011). A partir de estas publicaciones, se seleccionaron unas competencias adaptadas de Gómez (2015) y MEN (2013), y unos procesos que evalúan la presencia de estas.

Tabla 1. Elementos del empoderamiento docente.

\section{Dimensiones del saber Competencia Procesos}

1. Evidencia una apropiación y comprensión del saber matemático que enseña (Gómez, 2015)

Dimensión Cognitiva y Saber 2. Es capaz de aplicar el saber matemático a situaciones de la vida cotidiana del Epistemológica disciplinar estudiante (Gómez, 2015)

3. Usa o crea medios digitales específicos para dar significado a contenidos matemáticos (Carvajal et al., 2019, p. 289).

1. Propicia ambientes donde se construyan las ideas fundamentales sobre el saber matemático, más allá de las abstracciones, procedimientos y el aprendizaje de su aplicación (Cantoral y Reyes-Gasperini, 2014; Cantoral, Reyes-Gasperini, y Montiel, G., 2013; Reyes-Gasperini, y Cantoral, 2011).

2. Favorece el pensamiento reflexivo de sus estudiantes, motivándolos a expresar sus opiniones o posturas en determinadas situaciones (Gómez, 2015, p. 19).

Dimensión Social $\quad$ y gestión pedagógica
3. Reconoce las dificultades que se presentan en la construcción del conocimiento y desarrolla estrategias didácticas y tecnológicas para dicha construcción (ReyesGasperini y Cantoral, 2011).

4. Muestra capacidad para utilizar las TIc en la planeación, organización, administración y evaluación de manera efectiva de los procesos educativos (MEN, 2013, p. 33)

5. Evidencia capacidad para expresarse, establecer contacto y relacionarse en espacios presenciales y virtuales (MEN, 2013).

1. Reflexiona sobre los procesos de construcción del conocimiento, tanto propios como de sus alumnos (Gómez, 2015, p. 19)

2. Brinda ambientes de aprendizaje que faciliten la comprensión y construcción social del conocimiento (Gómez, 2015)

Reflexión sobre la práctica docente
3. Es capaz de promover estrategias para el trabajo individual y colaborativo con el apoyo de las TIC (Amaya et al., 2018, p.144)

4. Selecciona y utiliza de forma pertinente, responsable y eficiente una variedad de herramientas tecnológicas para fortalecer los procesos de enseñanza y aprendizaje (MEN, 2013)

5. Capacidad de utilizar las TIC para la transformación del saber y la generación de nuevos conocimientos (MEN, 2013, p.33)

Fuente: elaboración propia

En la dimensión epistemológica y cognitiva, con la competencia "saber disciplinar" se trabajó con tres procesos, donde 1 y 2 fueron tomados de Gómez (2015) y 3 de Carvajal et al. (2019). Dentro de la dimensión social, con las "competencias liderazgo" y "gestión pedagógica" se adaptaron cinco procesos, los cuales 1 y 3 son aportes de Cantoral y Reyes-Gasperini (2014), Cantoral, Reyes-Gasperini, y Montiel, G. (2013) y Reyes-Gasperini y
Cantoral (2011), el proceso 2 tomado de Gómez (2015) y los procesos 4 y 5 de Men (2013). Por último, en la dimensión didáctica, con la competencia "reflexión sobre la práctica docente" se ajustaron cinco procesos, donde 1 y 2 fueron tomados de Gómez (2015), 4 y 5 de MEN (2013) y el proceso 3 de Amaya et al. (2018). Así es como esto se evidencia de manera sintética en la Tabla 1. 


\section{Análisis de los cuestionarios realizados a los Formadores de Formadores (FF), Licenciados en Formación (LF) y Docentes en ejercicio (DE)}

Para realizar el análisis de los cuestionarios se tuvo en cuenta los elementos del empoderamiento docente identificados luego de la lectura cruzada en el análisis documental.

\section{Análisis del cuestionario FF}

Respecto a la dimensión epistemológica y cognitiva, los FF evidencian buen manejo del saber disciplinar y consideran que, antes de introducir al estudiante a un nuevo saber matemático, se hace necesario realizar una indagación de saberes previos y preconceptos. FF1 y FF2 recurren en ocasiones a proponer situaciones problemas relacionadas con el contexto del estudiante, tal como lo menciona Gómez (2015): el docente debe ser capaz de aplicar el saber matemático a situaciones de la vida cotidiana. En dichas situaciones, involucran el uso de herramientas tecnológicas o didácticas, con el fin de que estos relacionen y apliquen a su vida cotidiana lo aprendido en clase. Lo anterior refleja lo planteado por Carvajal et al. (2019): el docente debe ser capaz de usar o crear medios digitales específicos para dar significado a contenidos matemáticos.

La Figura 1 es una síntesis de las respuestas de los tres FF a las preguntas 1 y 2 del cuestionario. Estas preguntas abordan la dimensión epistemológica $y$ cognitiva de la problematización del saber.
La Figura 2 es evidencia de la respuesta del FF2 a las preguntas 1 y 2 del cuestionario.

Respecto a la dimensión social, el FF2 y FF3 reconocen que son importantes las acciones y el ambiente de aprendizaje que se construya en el aula, las estrategias de aprendizaje colaborativo, evaluación desde la autoevaluación, heteroevaluación y coevaluación. Destacan el deber del docente como guía del estudiante en el análisis matemático para que este fortalezca los procesos al momento de realizar una actividad de la materia y logre llegar a resultados correctos. El FF1 tiene en cuenta en la planeación de sus clases, para favorecer el logro de los saberes de sus estudiantes, los lineamientos, estándares, mallas de aprendizaje, etc., en matemáticas. Lo anterior hace referencia a lo planteado por Cantoral y Reyes-Gasperini (2014), Cantoral, Reyes-Gasperini, y Montiel, G. (2013), Reyes-Gasperini y Cantoral (2011) y Gómez (2015), en los procesos 1 y 2 de esta dimensión.

Por otro lado, los FF promueven la participación individual para hacer construcciones colectivas dentro del aula. Según lo observado, evidencian capacidad para expresarse y relacionarse con sus estudiantes, además utilizan distintos escenarios digitales para presentar la información, seleccionando dicho escenario o herramienta de acuerdo con lo que quieren desarrollar durante la clase. Esto se articula con lo planteado en los procesos 3 y 4 de esta dimensión.

En la Figura 3 se sintetizan las respuestas de las preguntas 3 y 7 del cuestionario a $\mathrm{FF}$, que abordan la dimensión social. 


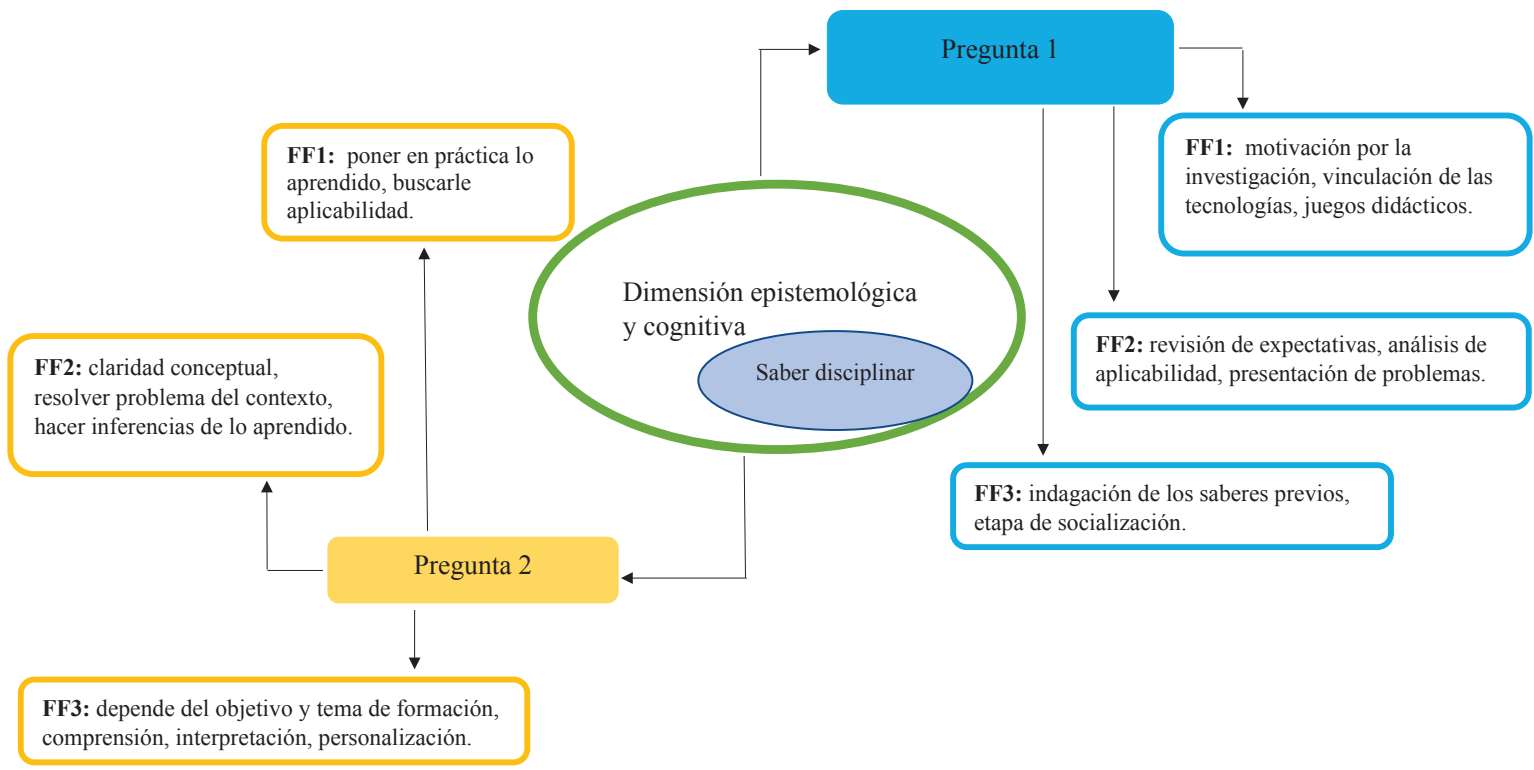

Figura 1. Síntesis de las respuestas 1 y 2 del cuestionario. Fuente: elaboración propia.

1. ¿Qué actividades realiza usted para introducir al estudiante a un nuevo saber matemático?

- Revisión de expectativas.

- Análisis de aplicabilidad del nuevo conocimiento mediante una situación problema relacionada con su contexto educativo laboral, vídeo que presente una aplicación, revisión de documento sobre avances en el tema u otro similar.

- Presentación de problema que se resuelva con el nuevo conocimiento para revisión de preconcepciones.

2. ¿Qué es lo que un estudiante debe saber hacer después de haber aprendido un tema matemático en su clase?

$>$ Claridad conceptual que permita la verbalización científica con ideas claras de lo que es y lo que no es lo estudiado.

Resolver problemas del contexto de las matemáticas.

$>$ Hacer inferencias de lo aprendido, por ejemplo aplicar el nuevo conocimiento en contextos distintos a los de matemáticas, es aplicar lo asimilado en otras áreas o situaciones cotidianas.

Figura 2. Respuesta FF2 a las preguntas 1 y 2. 


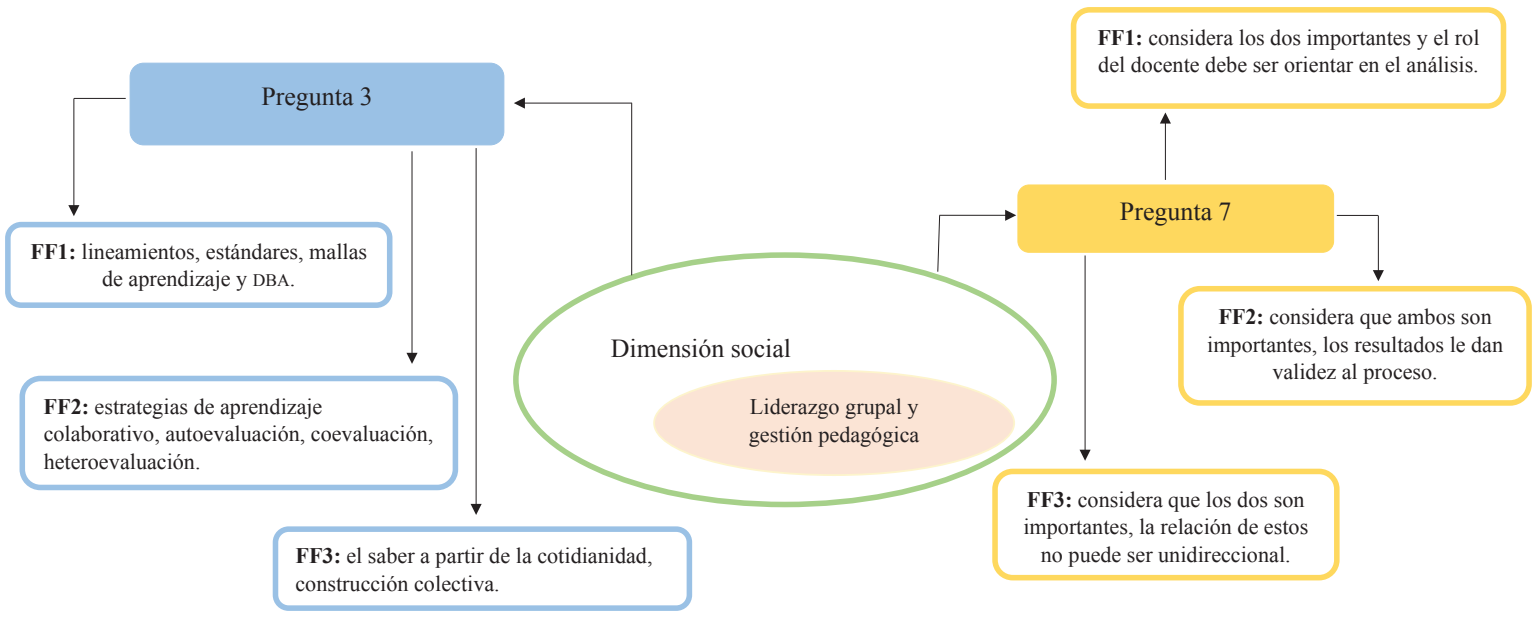

Figura 3. Síntesis de las respuestas 3 y 7 del cuestionario. Fuente: elaboración propia.

Respecto a la dimensión didáctica, los FF consideran que un buen manejo del saber disciplinar es vital dentro de los conocimientos que debe poseer un docente de matemáticas, sin ignorar los saberes pedagógicos, didácticos y tecnológicos que refuerzan los procesos de enseñanza de la matemática y permiten la construcción e implementación de estrategias para la mejora de esta. El FF3 destaca las competencias básicas de interpretación, argumentación y proposición que el docente debe manejar y desarrollar. Lo anterior es coherente con lo que plantea Gómez (2015) en el proceso 1 de esta dimensión. El FF1 respondió que el uso de herramientas TIC depende de si el docente lo considera o no.

Así mismo, los procesos 2, 3 y 4 de la dimensión didáctica se reflejan en las respuestas obtenidas. Los FF dejan ver que utilizan herramientas TIC para crear ambientes de aprendizaje colaborativo, de manera que se potencie la creatividad y otras competencias en los estudiantes. Además, optan por este tipo de herramientas afirmando que facilitan el proceso de enseñanza y aprendizaje. Resaltan la importancia de recursos didácticos análogos concretos como cubos, rompecabezas, etc., y otros recursos como esquemas y mapas mentales, acertijos matemáticos, cuadros sinópticos, entre otros. Los formadores coinciden en que sí han recibido capacitación en el uso de las TIC; sin embargo, uno de los formadores plantea que esta ha sido de manera autónoma. Pero todos reconocen la importancia de formarse y capacitarse en la innovación educativa con el uso de las TIC, reconociendo como nativos digitales a los estudiantes.

En la Figura 4 se sintetizan las respuestas de las preguntas 4, 5 y 6 del cuestionario a FF, que abordan la dimensión didáctica. 


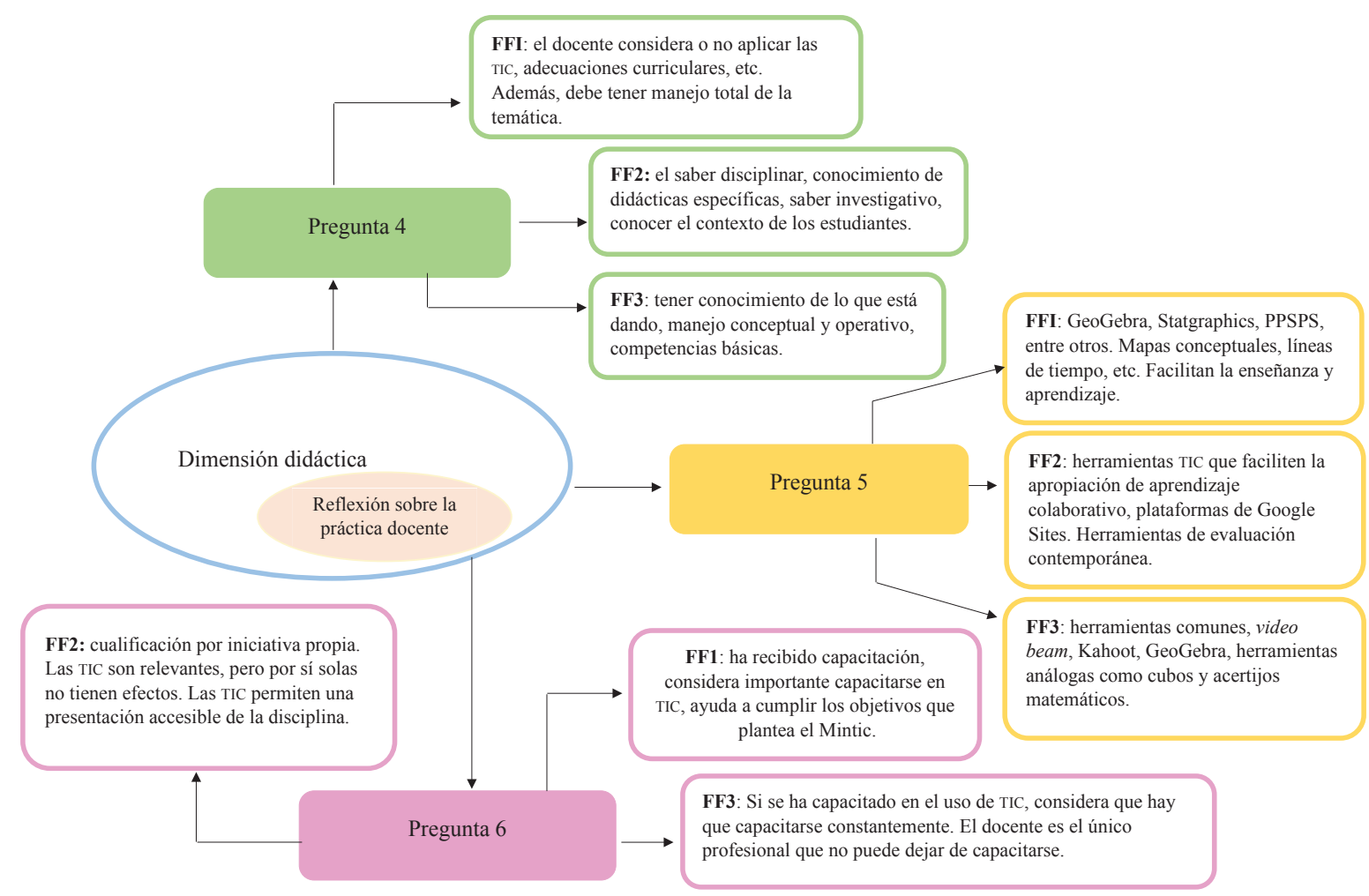

Figura 4. Síntesis de respuestas 4, 5 y 6 del cuestionario. Fuente: elaboración propia.

\section{Análisis del cuestionario LF}

Respecto a la dimensión epistemológica y cognitiva, los LF evidencian manejo del saber matemático y coinciden en que es necesario hacer una indagación de los saberes previos antes de introducir a los estudiantes a nuevas temáticas y encaminarse al objetivo de la clase. Solo el LF4 resaltó la necesidad de iniciar la enseñanza de un nuevo tema estableciendo relación entre docente, estudiante y contexto, lo que refleja lo planteado por Gómez (2015) en el proceso 2 de esta dimensión. Los demás LF coinciden en utilizar actividades lúdicas para realizar la exploración sobre los saberes previos de los estudiantes. Los LF consideran que el estudiante debe ser capaz de identificar cuándo aplicar o relacionar los conceptos aprendidos durante la clase en situaciones de su entorno. Sin embargo, en ninguna de las respuestas se evidencia el proceso 3 de esta dimensión. En la Figura 5 se encuentra la síntesis de las respuestas a las preguntas 1 y 2 obtenidas por los LF.

Las Figuras 6 y 7 muestran evidencia de las respuestas del LF4 y LF1 a las preguntas 1 y 2 respectivamente. 


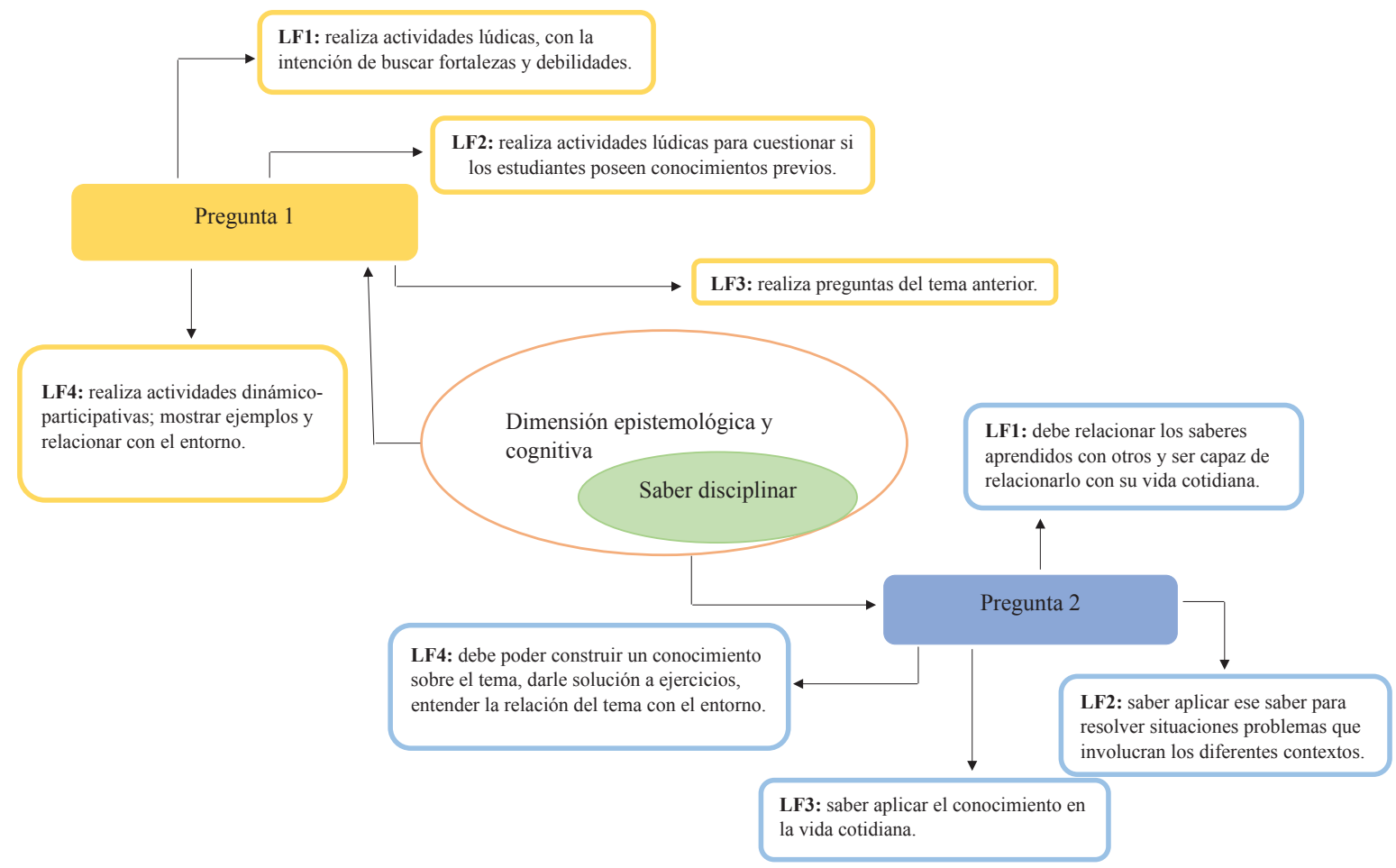

Figura 5. Síntesis de las respuestas 1 y 2 del cuestionario If. Fuente: elaboración propia.

\section{1. ¿Qué actividades realiza usted para introducir al estudiante a un nuevo}

saber matemático? Cuando no se fue el quiou de la enserianzos apundizaje del tema antenor, se haw un breve reparo o actividad dinámicux-partuipativa, y asi, constatar y reforzar los conoumientos previos neusanos de los estudeantes pano introducir el tema nuevo, en caso de que si se haya sido el quía anterior, las actividades de las clases antenor e's refleparan el apsehendimiento de dechos conotimientos por parte del es sudiante, de manera que se inicia, introduciendo los conceptos, explicando ejemplos, y mostrando su relacion con el entorno, dando un espaces para dispejar dudas y exponer sus apertes, permitiendo la interación con el docente, los demas istudiantes y su entomo.

Figura 6. Respuesta LF4 a la pregunta 1 del cuestionario. 


\section{2. ¿Qué es lo que un estudiante debe saber hacer después de haber aprendido un tema matemático en su clase?}

\section{El estudiante debe relacionar los saberes aprendidos con otros y que sea capaz de relacionarlos con la vida cotidiana, no es que los vaya aplicar siempre, pero al menos que pueda ver la estrecha relación de algunos fenómenos del diario vivir con lo aprendido en clases.}

Figura 7. Respuesta LF1 a la pregunta 2 del cuestionario.

Respecto a la dimensión social, el LF4 favorece el logro de los saberes de sus estudiantes siguiendo los estándares básicos de aprendizaje con metodologías necesarias para potencializar sus habilidades. Otros consideran que favorecen esos saberes motivándolos a investigar, generando espacio de aprendizaje colaborativo, a través de situaciones problema. A pesar de que todos los LF reconocen que es importante el proceso que realiza un estudiante en una actividad matemática, solo el LF4 destaca que el proceso da cuenta del aprendizaje, dificultades y errores del estudiante. Lo anterior da cuenta de lo planteado por Cantoral y Reyes-Gasperini (2014), Cantoral, Reyes-Gasperini, y Montiel, G. (2013), Reyes-Gasperini y Cantoral (2011) y Gómez (2015) en los procesos 1 y 2 de esta dimensión.

Los LF recurren a recursos tecnológicos en los casos donde se necesite observar de forma detallada características de conceptos matemáticos que analíticamente no se aprecian del todo, además del uso de videos explicativos, software (GeoGebra) y plataformas virtuales que les permitan a los estudiantes hacer construcciones propias del tema a tratar. Esto se relaciona con lo planteado en los procesos 4 y 5 de la dimensión social.

La Figura 8 muestra una síntesis de las respuestas a las preguntas 3 y 7 de los LF.

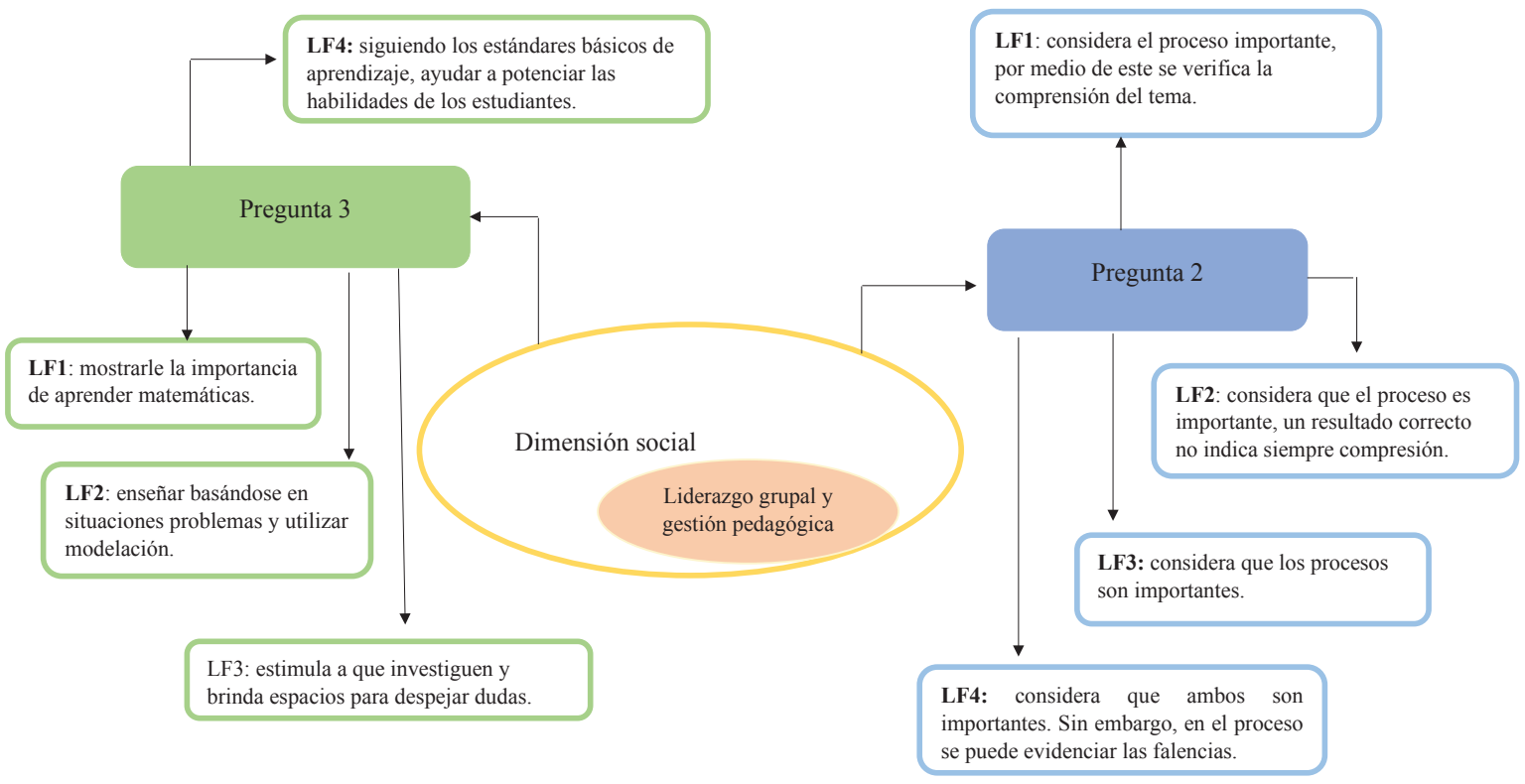

Figura 8. Síntesis de las respuestas 3 y 7 del cuestionario If. Fuente: elaboración propia. 
Respecto a la dimensión didáctica, los LF son coherentes en que, además de tener claro el saber matemático, se deben conocer e implementar diversas metodologías tanto pedagógicas como didácticas. Sin embargo, uno de los entrevistados destaca la importancia de manejar recursos tecnológicos, ya que las TIC actualmente han ocupado un lugar importante en la educación; además, dos LF resaltan la importancia de estar capacitados para la inclusión en el aula según sea el caso. Lo dicho está en consonancia con lo planteado por Gómez (2015) y Amaya et al. (2018) en los procesos 1 y 2 de esta dimensión.

Si bien reconocían la utilidad de los recursos tecnológicos, los LF señalaron que no siempre se pueden utilizar estas herramientas, puesto que el contexto en el que se trabaja no cuenta con los recursos tecnológicos requeridos. Por esto, recurren a materiales didácticos tangibles, y reconocen la necesidad de seguirse capacitando en el adecuado uso de las TIC como medio para la innovación en el aula, ya que estas generan interés y desarrollan competencia. Lo anterior refleja lo planteado en los procesos 4 y 5 de la dimensión didáctica.

La Figura 9 hace referencia a las respuestas dadas por LF2 en la pregunta 4 del cuestionario. La Figura 10 muestra una síntesis de las respuestas obtenidas por los LF en las preguntas 4, 5 y 6 .

\section{Según su experiencia ¿Qué conocimientos considera debe manejar el profesor de Matemáticas? ¿Por qué?}

Hoy en día, el docente de matemáticas no solo debe dominar los conocimientos específicos de esta área, sino que además debe estar apropiado de los conocimientos pedagógicos porque estos conocimientos son los que le permitirán realizar las adaptaciones necesarias para que sus estudiantes comprendan con mayor facilidad el tema que se esté estudiando.

Además, y lo digo basado en mi práctica pedagógica, el docente de matemáticas debe ser capaz de manejar los recursos tecnológicos, y aún más importante, saber utilizarlos transversalmente para facilitar el aprendizaje de los estudiantes. Es necesario que el docente desarrolle esta habilidad ya que las TICs han permeado el campo de la educación y por lo que se hace necesario estar empoderados de ellas.

Por último, es importante que el docente tenga conocimiento sobre la inclusión de los estudiantes con discapacidades, limitaciones y talentos excepcionales, ya que hoy en día tanto en las instituciones públicas como privadas, los niños con estas características son incluidos dentro de las aulas con niños regulares, por lo cual el docente debe estar capacitado para sobrellevar estas situaciones con el objetivo de incluirlos y no excluirlos.

Figura 9. Respuesta LF2 a la pregunta 4 del cuestionario. 


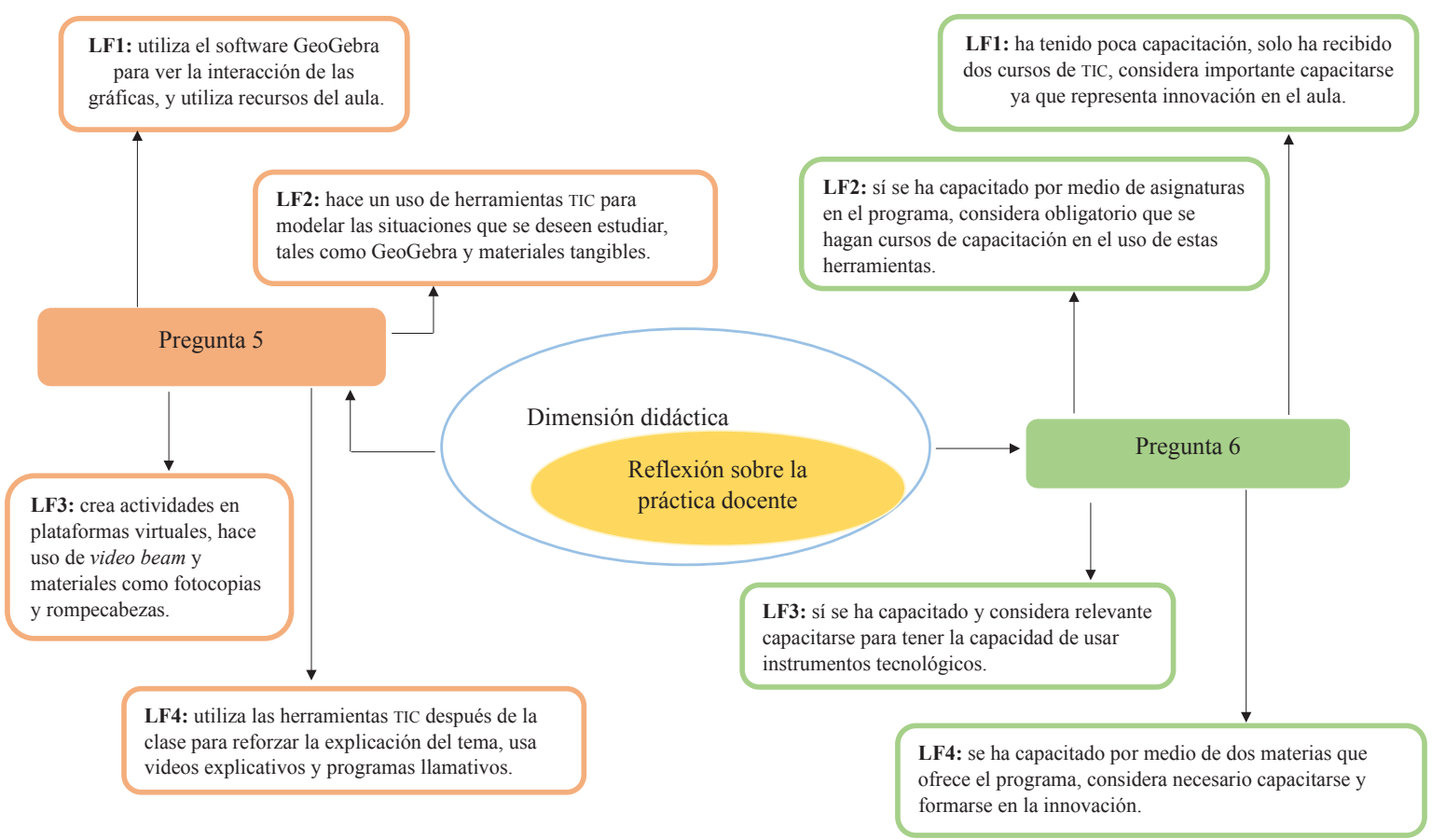

Figura 10. Síntesis de las respuestas 5 y 6 del cuestionario If. Fuente: elaboración propia

\section{Análisis cuestionario DE}

Respecto a la dimensión epistemológica y cognitiva, los tres DE evidencian manejo del saber disciplinar y destacan cuán importante es hacer una indagación de saberes previos a través de situaciones problema basadas en la vida cotidiana del estudiante antes de introducirlo a una nueva temática, para que este vea la relación con su entorno y sea capaz de aplicar lo aprendido en clase en otras situaciones de su vida. El DE1 destaca que la introducción del estudiante a una nueva temática depende de la complejidad del tema, en ocasiones se apoya de herramientas TIC. Lo expresado por los docentes refleja lo planteado en el proceso 1 y 2 de esta dimensión. Sin embargo, en las observaciones solo un DE evidenció el proceso 2 y solo el DE1 dio cuenta del proceso 3, ya que involucra tecnología al tratar una nueva temática. En la Figura 11 se muestra una síntesis de las respuestas a las preguntas 1 y 2 del cuestionario aplicado a los DE del departamento del Atlántico.

Respecto a la dimensión social, el DE1 y DE2 utilizan las redes sociales para comunicarse con sus estudiantes. Por estas envían actividades. Resaltan que es importante tener en cuenta el contexto al que el estudiante pertenece para elegir las herramientas tecnológicas con las que se va a trabajar. Hacen uso de las plataformas institucionales, y otras apps que no requieran conectividad, el DE1 realiza videos tutoriales propios en relación con el tema a tratar. El DE3 destaca que las herramientas tecnológicas que utiliza en sus clases dependen de las habilidades que pretende desarrollar en los estudiantes. En las respuestas obtenidas se evidencian los procesos 1, 3 y 4 de esta dimensión, sin embargo, en las observaciones solamente un DE fomentó la participación de sus estudiantes, lo que se disocia con lo expresado en la entrevista. En la Figura 12 se muestra una síntesis de las respuestas de los DE a la pregunta 4.

Respecto a la dimensión didáctica, como docentes en ejercicio, los DE han recibido capacitación en el uso de las TIC por parte de programas del Mintic. El DE2 considera que la capacitación es permanente y de manera autónoma se ha capacitado en cursos gratuitos online, al igual que el DE1 que se ha capacitado por medio de 
diplomados y maestrías en Políticas TIC. El DE3 resalta que el problema radica en que las instituciones no cuentan con recursos tecnológicos necesarios para el desarrollo de unas buenas prácticas. Lo anterior refleja lo planteado por Gómez (2015) en el proceso 1 de esta dimensión. Solo el DE2 resalta el porqué de la importancia de capacitarse e implementar las TIC y promueve el uso de dispositivos móviles en su clase, lo que da cuenta del proceso 4 y 5 de esta dimensión, sin embargo, en las observaciones muestran que no utilizan de manera pertinente las TIC, puesto que utilizaron estas herramientas solo para mostrar la guía del tema a desarrollar.

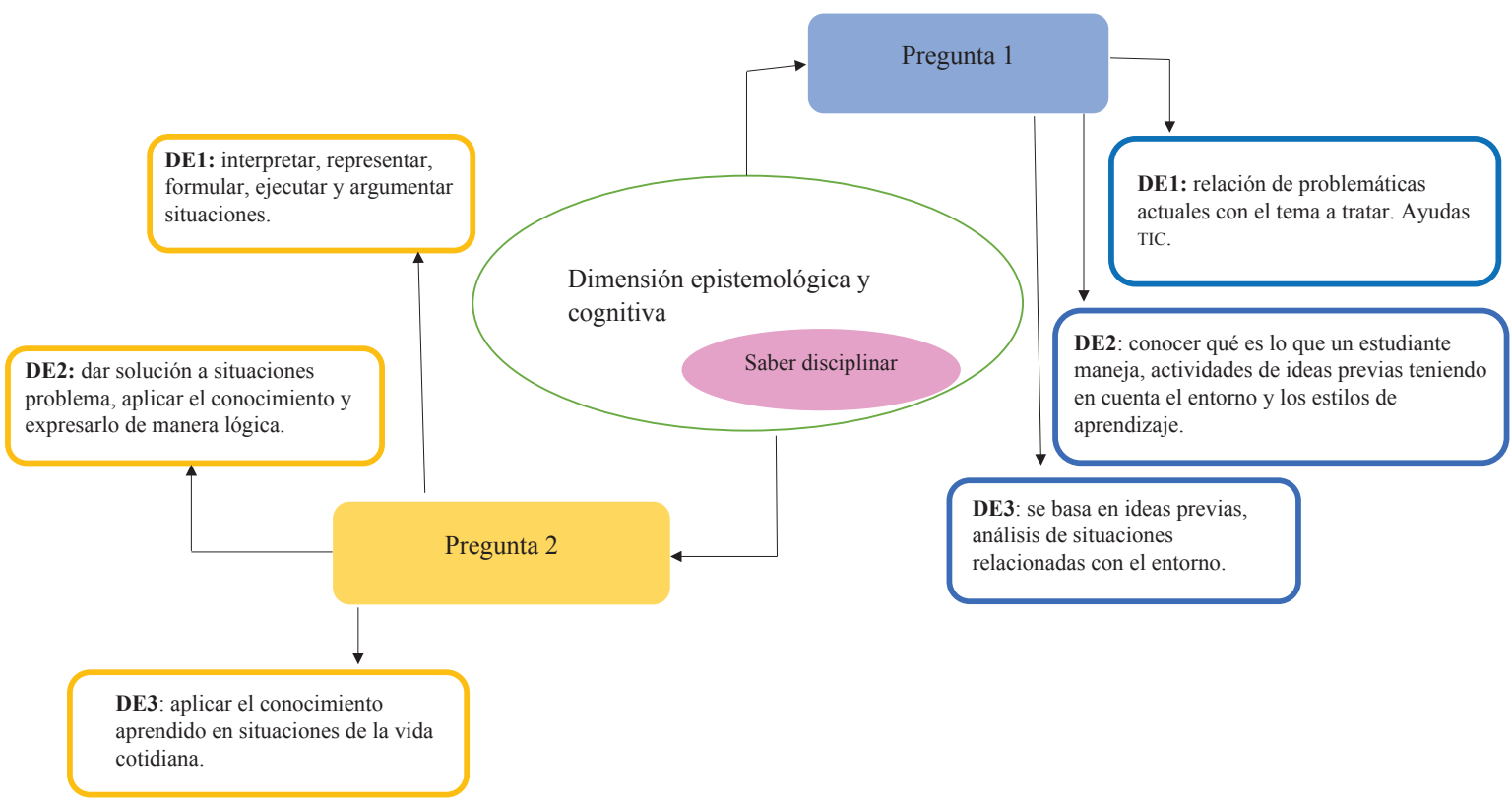

Figura 11. Síntesis de respuesta a preguntas 1 y 2 del cuestionario a DE. Fuente: elaboración propia

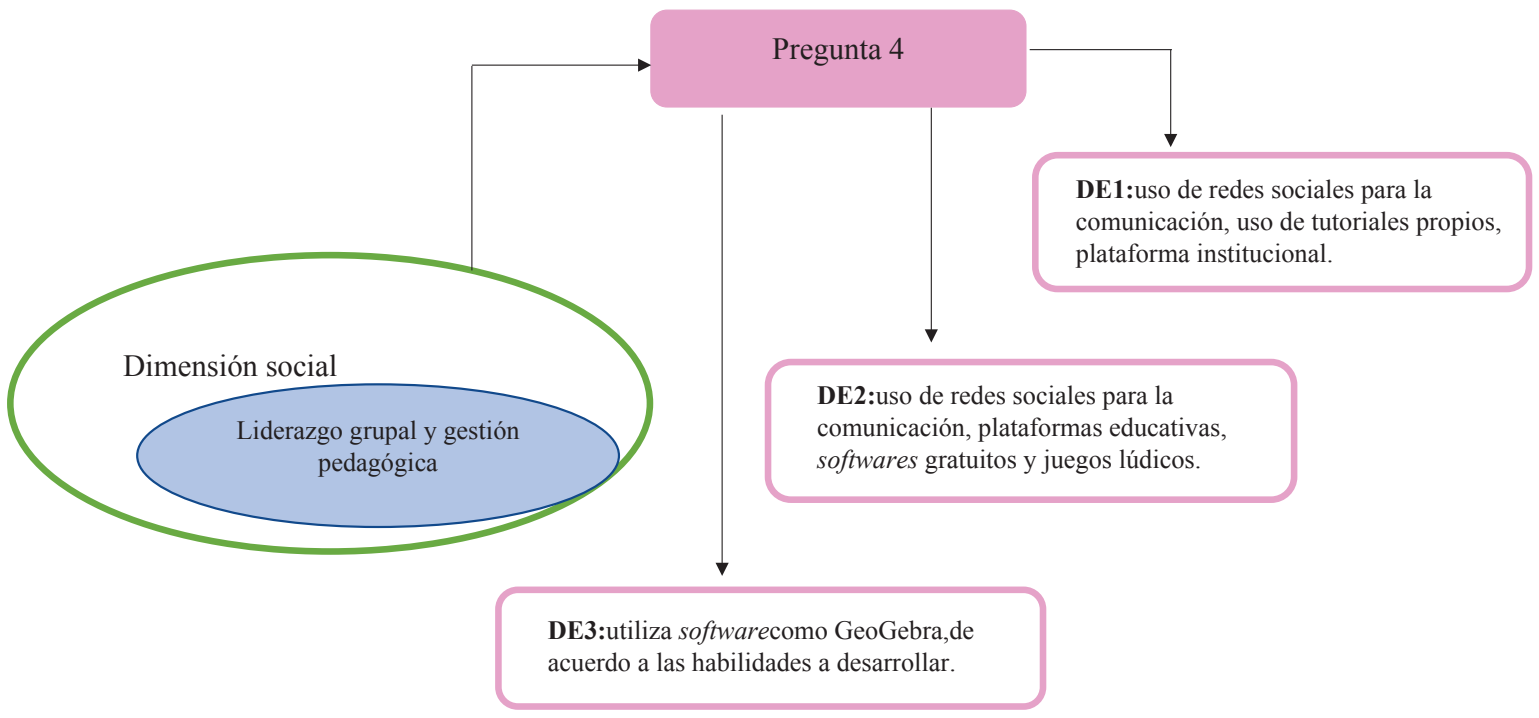

Figura 12. Síntesis de las respuestas a la pregunta 4 del cuestionario a los de. Fuente: elaboración propia 
Del mismo modo, el DE2 y DE3 manifiestan que un profesor de matemáticas debe conocer y manejar los conocimientos específicos del área, así como las herramientas didácticas y tecnológicas. Sin embargo, el DEl considera que el profesor de matemáticas debe dominar el ámbito pedagógico, la capacidad de adaptarse al contexto y reconocer los diferentes estilos de aprendizaje, reconocer la evaluación como proceso integral incluso para los procesos de enseñanza. Son coherentes en que el profesorado en la era digital debe adaptarse a las distintas realidades, reformular la manera de enseñar teniendo en cuenta las diferentes maneras de aprender, ser facilitador y constructor de conocimiento. Otras de las funciones destacadas por DE2 es tener empatía con el trabajo colaborativo, conocimientos en informática y manejo curricular. Lo anterior da cuenta del proceso 1 y 2 de esta dimensión.

En la Figura 13 se muestra evidencia de la respuesta del DE2 a la pregunta 5 del cuestionario y la Figura 14 muestra una síntesis de las respuestas obtenidas de los DE a las preguntas 3 y 6 .

Con base en los resultados obtenidos, es pertinente afirmar que no hay un amplio desarrollo de los procesos de empoderamiento docente en la enseñanza de la matemática, en la medida en que no se brindan ambientes en los que se favorezca de forma significativa el pensamiento reflexivo de los estudiantes. Del mismo modo, a las TIC, en la mayoría de los casos, no se les hace un uso pertinente dentro de las planeaciones y los profesores no muestran de manera efectiva la capacidad de expresarse y establecer contacto con estos espacios virtuales.

Teniendo en cuenta los resultados obtenidos en los análisis de la investigación, cabe afirmar que los formadores de formadores, licenciados en formación inicialy los docentes en ejercicio en el marco del empoderamiento docente, evidencian divergencias entre sus discursos y lo observado en la práctica. Pese a que reconocen la importancia de mantenerse en formación continua, particularmente en el uso de recursos tecnológicos, considerando como nativos digitales a los estudiantes y en la mayoría de los casos se capacitan en el uso de las Tic de manera autónoma, aún se evidencian prácticas en las que estos recursos se quedan en el uso instrumental de la herramienta. Por esto, en investigaciones anteriores se manifiesta la necesidad de reflexionar sobre las causas que limitan el uso de las Tic, teniendo en cuenta las competencias digitales de los docentes en los procesos de enseñanza (Villarreal et al., 2019).

Otro aspecto para destacar dentro de los hallazgos es que resulta notorio el conocimiento de recursos tecnológicos por parte de los docentes. Además, reconocen las TIC como generadoras de cambios significativos en los procesos de enseñanza y aprendizaje; sin embargo, no brindan ambientes donde se ponga de manifiesto su uso oportuno y eficaz, especialmente por parte de los profesores en ejercicio, quienes fueron los que demostraron menos apropiación de estas en el aula. Esto evidencia la falta de formación y dominio por parte de los profesores en las competencias TIC, puesto que aún caen en actividades repetitivas y no muy innovadoras, pese a que cuentan con recursos tecnológicos.

Teniendo en cuenta que el empoderamiento docente es el proceso que le permite al profesor adueñarse del saber que enseña a través de su problematización, potencializando su desarrollo profesional e integral, promoviendo la innovación en el aula y posibilitando la creación herramientas para motivar a sus estudiantes y guiarlos hacia un aprendizaje significativo (Cantoral y Reyes-Gasperini, 2016), con base en los resultados obtenidos consideramos pertinente que los docentes de los diferentes escenarios educativos lo conozcan y trabajen en ello para potencializar sus habilidades cognitivas, pedagógicas y tecnológicas. En este sentido, si los profesores de matemáticas hacen una integración de las dimensiones del saber serán capaces de reconocer y utilizar las TIC de manera pedagógica y eficiente en los procesos de enseñanza. 
5. ¿Cómo docente ha tenido un proceso de sensibilización en el uso de herramientas TIC por parte de la institución como apoyo a los procesos de enseñanza? ¿Cómo ha sido ese proceso? En caso de que su respuesta sea negativa, ¿Ha tenido la iniciativa de cualificarse en el uso de estas Le herramientas por otros medios? ¿Cuáles? He participado en copocitociones en el uso de herramientas ticnologicas, a nivel nacional con creaTic, en softuare libre, manejo de simuladores, capacitación de la plalaforma SiAN365, simpre he sido lider en el manejo de celulares elentro del qula. Considero que la capacitacion es permanente, la idea es seguir qu formación porque estar siempre a la vanguardia con los que estar siempre a la vanguardia con los

Figura 13. Respuesta DE2 a la pregunta 5 del cuestionario.

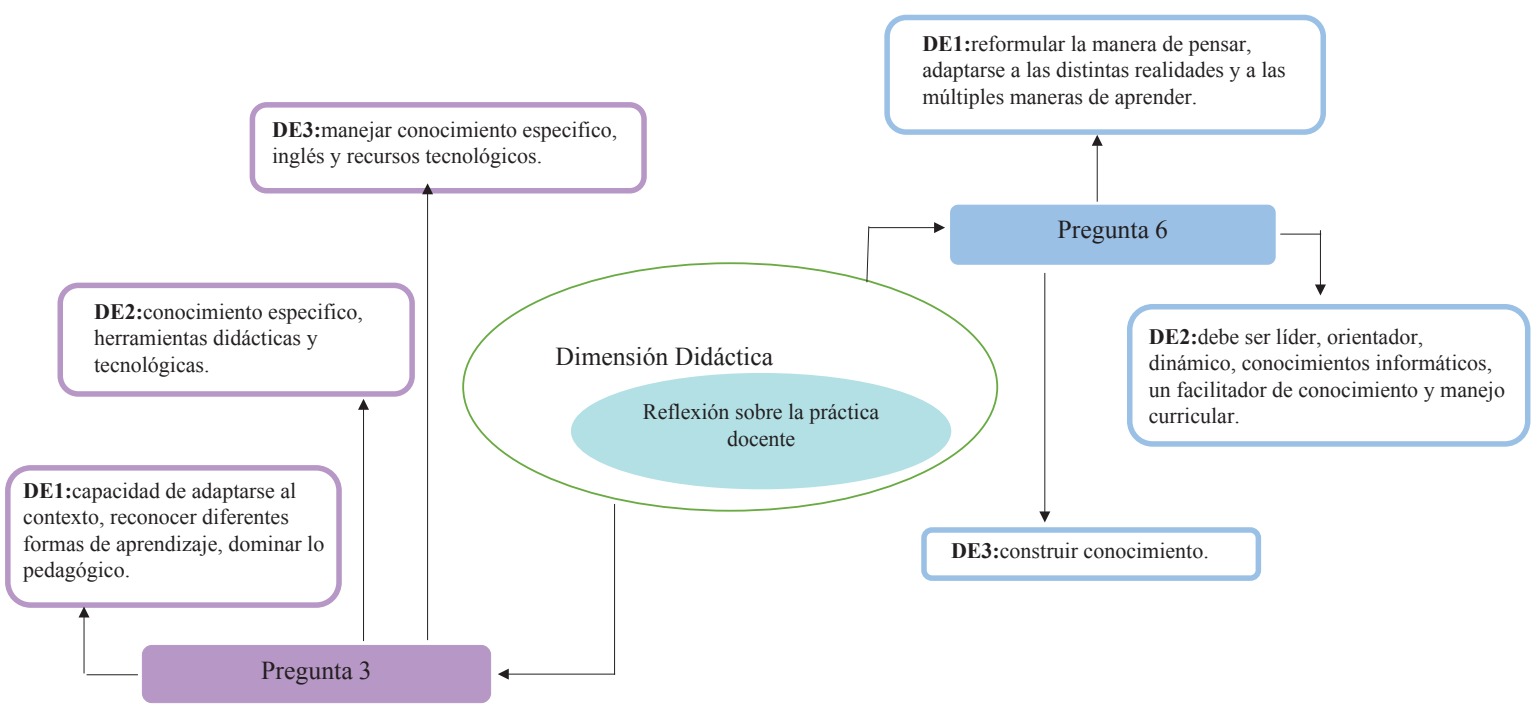

Figura 14. Síntesis de las respuestas a las preguntas 3 y 6 del cuestionario a DE. Fuente: elaboración propia

\section{Conclusión}

Es claro que el papel del docente es fundamental dentro del proceso de enseñanza y aprendizaje. Por tanto, el profesor debe estar preparado para los retos que este proceso presenta, debido a los cambios de la sociedad. Las TIC han provocado transformaciones en la actualidad, y los docentes son quienes deben alcanzar las competencias necesarias para que su uso en el ámbito educativo sea efectivo y pertinente. A partir de la revisión de la literatura y de los hallazgos obtenidos en los análisis de esta investigación es pertinente mencionar las siguientes conclusiones: a) los docentes 
no hacen uso idóneo de los recursos tecnológicos y, en casos particulares, las instituciones educativas carecen de infraestructura tecnológica, lo que evidencia la aún existente "brecha digital"; b) aunque se reconocen las TIC como herramientas de apoyo a los procesos de enseñanza y aprendizaje, se hace necesario reforzar las competencias tecnológicas y digitales desde la formación inicial del profesorado como aspecto importante dentro del proceso de empoderamiento docente; c) sigue latente la necesidad de que los profesores de todas las áreas, en especial de matemáticas, estén cualificados para afrontar los nuevos desafíos y las transformaciones en materia de Tic que trae consigo la era digital y los acontecimientos sociales; como el que se presenta hoy en el mundo a causa del COVID-19, por el cual el sistema educativo y todos sus actores se han visto obligados a utilizar los recursos tecnológicos como apoyo a los procesos de enseñanza.

\section{Referencias}

Alvis, J., Aldana, E. y Solar, H. (2019). Ambientes de aprendizaje: un articulador para el desarrollo de competencias matemáticas. Espacios, 40(21), 1-13. https://www. revistaespacios.com/a19v40n21/19402108.html

Amaya, A.; Zúñiga, E.; Salazar, M. y Ávila, A. (2018). Empoderar a los profesores en su quehacer académico a través de certificaciones internacionales en competencias digitales. Apertura, 10(1), 104-115. doi: http:// dx.doi. org/10.18381/Ap.v10n1.1174

Banoy, W. (2019). Uso pedagógico de las Tecnologías de la Información y la Comunicación (TIC) y su influencia en el aprendizaje significativo de estudiantes de media técnica en Zipaquirá, Colombia. Revista Academia y Virtualidad, 12(2), 23-46. doi: https://doi.org/10.18359/ ravi.4007

Carvajal, S., Giménez, J., Font, V. y Breda, A. (2019). La competencia digital en futuros profesores de matemáticas. En E. Badillo, N. Climent, C. Fernández y M.T. González (Eds.), Investigación sobre el profesor de matemáticas: formación, práctica de aula, conocimiento y competencia profesional (pp. 285-306). Salamanca: Ediciones Universidad Salamanca.

Cantoral, R y Reyes-Gasperini, D. (2012a). Matemáticas y Práctica Social: construcción social del conocimiento matemático. Novedades Educativas, (261), 60-65. https://bit.ly/3fZ48Ns
Cantoral, R. y Reyes-Gasperini, D. (2012b). Educación y didáctica: el caso del empoderamiento docente en Matemáticas. Congreso Internacional y VIII Congreso Nacional de Investigación en Educación, Pedagogía y Formación docente, Bogotá, Colombia, 200-213.https:// www.researchgate.net/publication/261995955_Educacion_y_Didactica_el_caso_del_empoderamiento_docente_en_matematicas

Cantoral, R y Reyes-Gasperini, D. (2014). Socioepistemológica y empoderamiento: la profesionalización docente desde la problematización del saber matemático. Bolema, 28(48), 360-382. doi:_http://dx.doi.org/10.1590/1980-4415v28n48a14

Cantoral, R y Reyes-Gasperini, D. (2016). Empoderamiento docente: la práctica docente más allá de la didáctica... ¿Qué papel juega el saber en una transformación educativa? Revista de la Escuela de Ciencias de la Educación, 2(11), 2362-3349. doi: http://dx.doi. org/10.35305/rece.v2i11.265

Cantoral, R., Reyes-Gasperini, D., y Montiel, G. (2013). Profesionalización docente en Matemáticas. El empoderamiento docente: una mirada emergente. En C. Dolores, M. García, J. Hernández y L. Sosa (Eds.). Matemática Educativa: la formación de profesores (pp. 153-172). Ediciones Diaz de Santos.

Fiallo, J. (2015). Acerca de la investigación en educación matemática desde las tecnologías de la información y la comunicación. Actualidades Pedagógicas, (66), 6983. doi: https://doi.org/10.19052/ap.3436

Gómez, J. (2015). El empoderamiento docente: una opción para la apropiación de la práctica educativa del profesor de matemáticas. [Tesis de maestría, Tecnológico de Monterrey Santiago de Querétaro, México]. Archivo digital. https://repositorio.tec. $\mathrm{mx} /$ bitstream/handle/11285/621253/Tesis_JuanPabloGomezEstrada.pd$\mathrm{f}$ ? sequence $=3 \&$ is Allowed $=\mathrm{y}$

Grisales-Aguirre, A. (2018). Uso de recursos Tic en la enseñanza de las matemáticas: retos y perspectivas. Revista Entramado, 14(2), 198-214. doi: https:/doi. org/10.18041/1900-3803/entramado.2.4751

Jandric, P. (2020). Deschooling. En: M. A. Peters (ed.), Encyclopedia of Teacher Education. Singapur: Springer. doi: https://doi.org/10.1007/978-981-13-1179-6_115-1

Jiménez, V. (2012). El estudio de caso y su implementación en la investigación. Revista internacional de investigación en ciencias sociales, 8(1), 141-150.

Ley General de Educación. (1994, 8 de febrero). Congreso de la República de Colombia. Diario Oficial n. ${ }^{\circ}$ 41.214. https://www.mineducacion.gov.co/1621/articles-85906_archivo_pdf.pdf 
Llinares, S. (2012). Construcción de conocimiento y desarrollo de una mirada profesional para la práctica de enseñar matemáticas en entornos en línea. Avances de Investigación en Educación Matemática, (2), 53-70. doi: https://doi.org/10.35763/aiem.v1i2.18

Llinares, S. (2018). Conocimiento, competencia docente del profesor de matemáticas y llegar a ser un formador de profesores. Revista Avances de la Investigación en Educación Matemática (13), 1-3.

Lopes, N. y Gomes, A. (2018). Experimentar con las TIC en la formación inicial de profesores. Revista Educatio siglo XXI, 36(3), 255-274. doi: http://dx.doi.or$\mathrm{g} / 10.6018 / \mathrm{j} / 349991$

López, L., Rojas, M., Correa, L. y Arbeláez, D. (2017). Normatividad y estrategias de formación de profesores en tecnologías de la información y la comunicación. Revista Academia y Virtualidad, 10(1), 79-94. https://doi. org/10.18359/ravi.4007

Ministerio de Educación Nacional [MEN] (2006). Estándares básicos de competencias. https://www.mineducacion.gov.co/1621/articles-340021_recurso_1.pdf

Ministerio de Educación Nacional, Colombia [MEN]. (2013). Competencias TIC para el Desarrollo Profesional Docente. https:/www.mineducacion.gov.co/1759/ articles-339097_archivo_pdf_competencias_tic.pdf

Ministerio De Educación Nacional, Colombia [MEN]. (2014). Lineamientos de calidad para las Licenciaturas en Educación. Colombia. https://www.mineducacion. gov.co/1759/articles-357233_recurso_1.pdf

Ministerio de Educación Nacional, Colombia [MEN]. (2019). Decreto 1330/2019. Por el cual se sustituye el Capítulo 2 y se suprime el Capítulo 7 del Título 3 de la Parte 5 del Libro 2 del Decreto 1075 de 2015 -Único Reglamentario del Sector Educación. https://www.mineducacion.gov.co/1759/articles-387348_archivo_pdf. pdf

Ministerio de Educación Nacional, Colombia [MEN]. (2020). Micrositios Institucionales- Covid-19. https:// www.mineducacion.gov.co/portal/micrositios-institucionales/Covid-19/393903:Informacion-de-interes

Molina, S. e Iglesias, M. T. (2014). Una innovación didáctica en la universidad incorporando herramientas tecnológicas en Experiencias de Innovación Docente Universitaria. España: Ediciones Universidad de Salamanca. http://buscoinfobjcu.uca.edu.ni/Record/ EBC3222962

Moreno, J. (2019). Formación docente en Competencias tecnológicas en la era digital: Hacia un impacto sociocultural. [Tesis de Maestría, Universidad Cooperativa De Colombia]. Archivo digital. https://repository.ucc.edu.
co/bitstream/20.500.12494/12250/1/2019_Formaci\%C3\%B3n_Docente_Tecnolog\%C3\%ADas.pdf

Ñaupas, H., Mejía. E., Novoa, E. y Villagómez, A. (2014) Metodología de la investigación cuantitativa-cualitativa y redacción de la tesis. Bogotá: Ediciones de la U. $4^{\mathrm{a}}$ Edición.

Organización de las Naciones Unidas para la Educación, la Ciencia y la Cultura. [Unesco]. (2019). Marco de competencias de los docentes en materia de TIC. https://bit. ly/3qXJLoG

Quintana, A. (2006). Metodología de la Investigación científica Cualitativa. En A. Quintana y W. Montgomery (eds.), Psicología: Tópico de Actualidad (pp. 47-84). http://www.ubiobio.cl/miweb/webfile/media/267/3634305-Metodologia-de-Investigacion-Cualitativa-A-Quintana.pdf

Radford, L. (2018). Semiosis and Subjectification: The Classroom Constitution of Mathematical Subjects. En N. Presmeg, L. Radford, M. Roth y G. Kadunz, Signs of signification. Semiotics in mathematics education research (pp. 21-35). Cham, Switzerland: Springer. doi: https://doi.org/10.1007/978-3-319-70287-2_2

Reyes-Gasperini, D. y Cantoral, R. (2011). Empoderamiento docente desde una visión Socioepistemológica: Estudio de los factores de cambio en las prácticas del profesor de matemáticas. [Tesis de maestría, Centro de Investigación y de Estudios Avanzados del Instituto Politécnico Nacional, México]. Archivo digital. https:// www.researchgate.net/publication/262487299_Empoderamiento_docente_desde_una_vision_Socioepistemologica_Estudio_de_los_factores_de_cambio_en_ las_practicas_del_profesor_de_matematicas

Rodríguez, M. E. (2016). La Función social de la enseñanza de la matemática desde la matemática-cotidianidad- y pedagogía integral. Eleuthera, 15, 34-45. doi: 10.17151/ eleu.2016.15.3.

Rule, P. y Mitchell, J. (2015). A necessary Dialogue: Theory in case study research. International Journal of Qualitative, 14(4), 1-11. doi: https:/doi. $\operatorname{org} / 10.1177 / 1609406915611575$

Teräs, M., Souranta, J., Teräs, H. y Curcher, M. (2020). Post-Covid-19 Education and Education Technology 'Solutionism': a Seller's Market. Postdigital Science and Education. Springer, 2, 863-878, 863-878. doi: https:// doi.org/10.1007/s42438-020-00164-x

Torres, C. (2017). La implicación de las TIC en la educación: alcances, limitaciones y prospectiva. Revista Iberoamericana para la Investigación y el Desarrollo Educativo, 8(15), 861-876. doi: https://doi.org/10.23913/ride. v8i15.324 
Thurm, D. y Barzel, B. (2020). Effects of a Professional Development Program for Teaching Mathematics with Technology on Teachers' Beliefs, Self-Efficacy and Practices. ZDM Mathematics Education, 52, 14111422. doi: https://doi.org/10.1007/s11858-020-01158-6

Valero, P. (2017). El deseo de acceso y equidad en la educación matemática. Revista Colombiana de
Educación, (73), 99-128. doi: http://dx.doi.org/10.17227/01203916.73rce97.126

Villarreal-Villa, S., García-Guliany, J., Hernández-Palma, H. y Steffens-Sanabria, E. (2019). Teacher Competences and Transformations in Education in the Digital Age. Formación universitaria, 12(6), 3-14. https://dx. doi.org/10.4067/S0718-50062019000600003 